\title{
在下関漁船の無線航海計器に就で
}

\section{On The Radio navigational aids set on fishing boats at Shimonoseki harbor.}

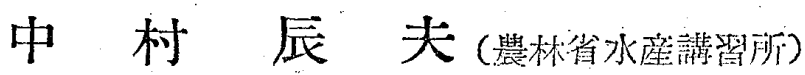

\begin{abstract}
After having investigated the real circumstances of setting wireless navigational aids about 413 fishing boats amounting to the ratio of $90 \%$ of the whole boats which have the chief base at Shimonoseki harvor, we have confirmed the following results.

1. Radio Direction Finder

$32 \%$ of the whole investigated boats have the aid. The items of various boats are as follows. Trawlers : 100\%, Danish seine boats : 83\% Purse seine boats : $57 \%$

2, Fish Finder

$20 \%$ of the whole investigated boats have the aid. The items of various boats are as followa. Trawlers: 59\% Danish seine boats : 9\%, Purse seine boats: $80 \%$, Fish carryers following to Purse seine boat: $20 \%$.

3. Marine Radar

Only one of Danish seine boats was set up with the aids at Feb. 1952, moreover, one of them are on the way of being set up and two Trawlers and a Danish seine boat are planned to set up this aids. For the future, there is a distinct tendency to set up many more to them in the fishing circles.
\end{abstract}

序言

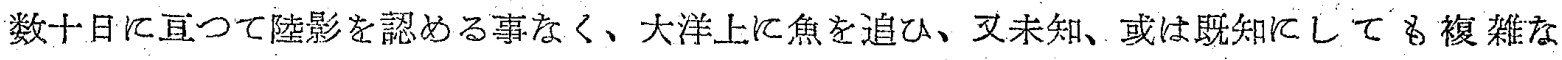

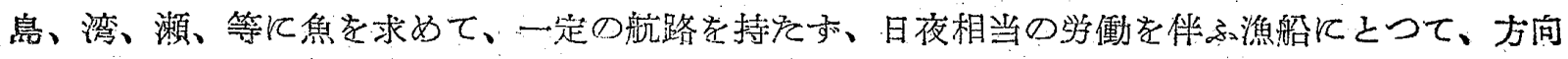
探知機、音響測深儀 (魚群探知機)、レーダー、ロラン、なぞの無線航海計器结、単江船舶の安

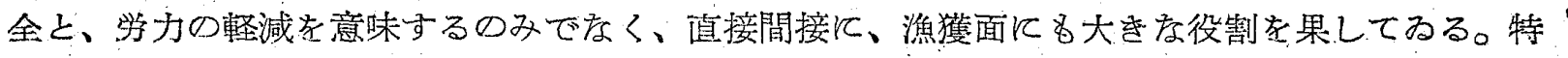
に戦後の、マッカーサーラインイ低る、限られそ海区内での操業は、漁業者が生をて行く上の、

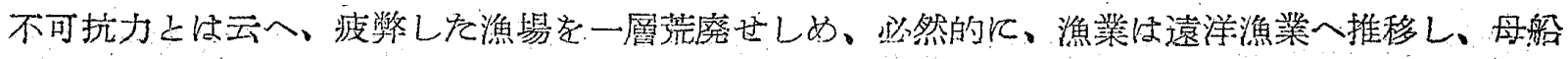

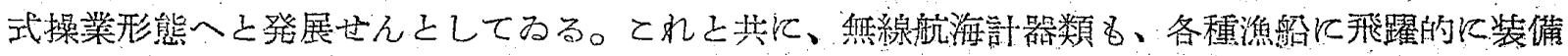

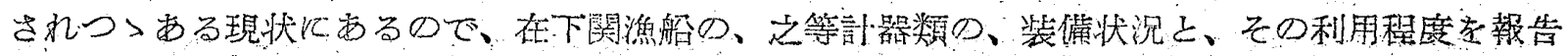
するととした。

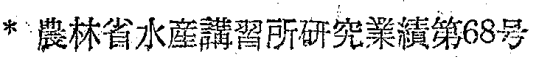




\section{調 查 資 料}

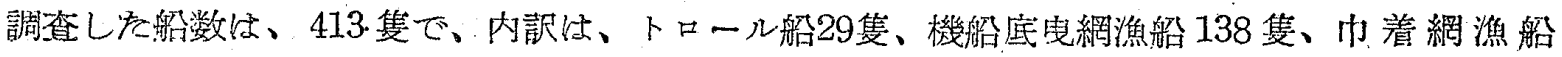
80隻、及门潧網漁船に附随する、小取船、運搬船 116 隻で、下関を主をる根拠地とする漁船の、

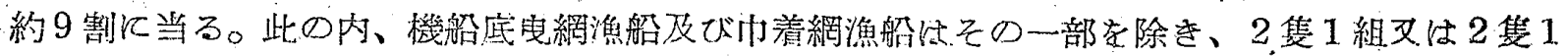

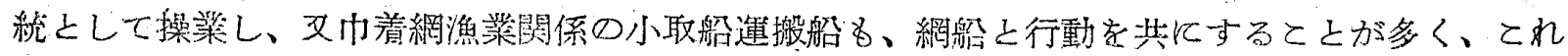
等は大き教観点よりみて、1隻の船と云るととが出来る。

\section{1, 方 向 探 知 機}

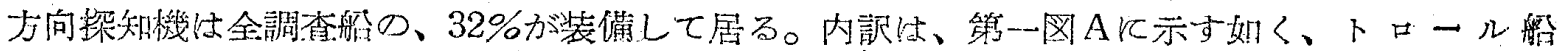

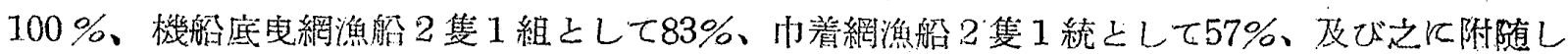

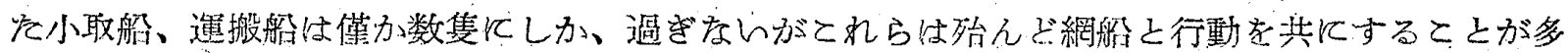

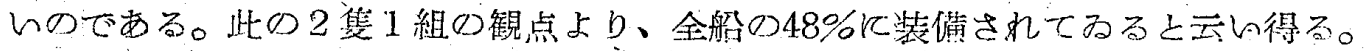

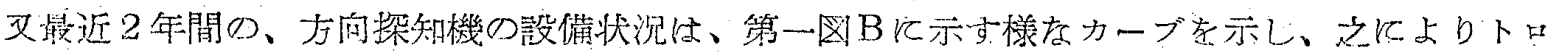

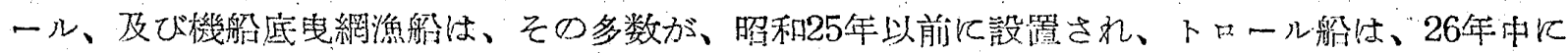

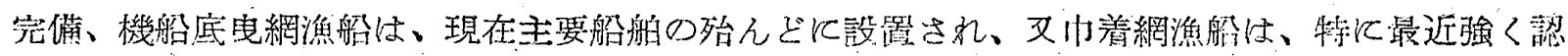
識され、設罯数つ40\%は、今年に入つてから装備されを事が分る。
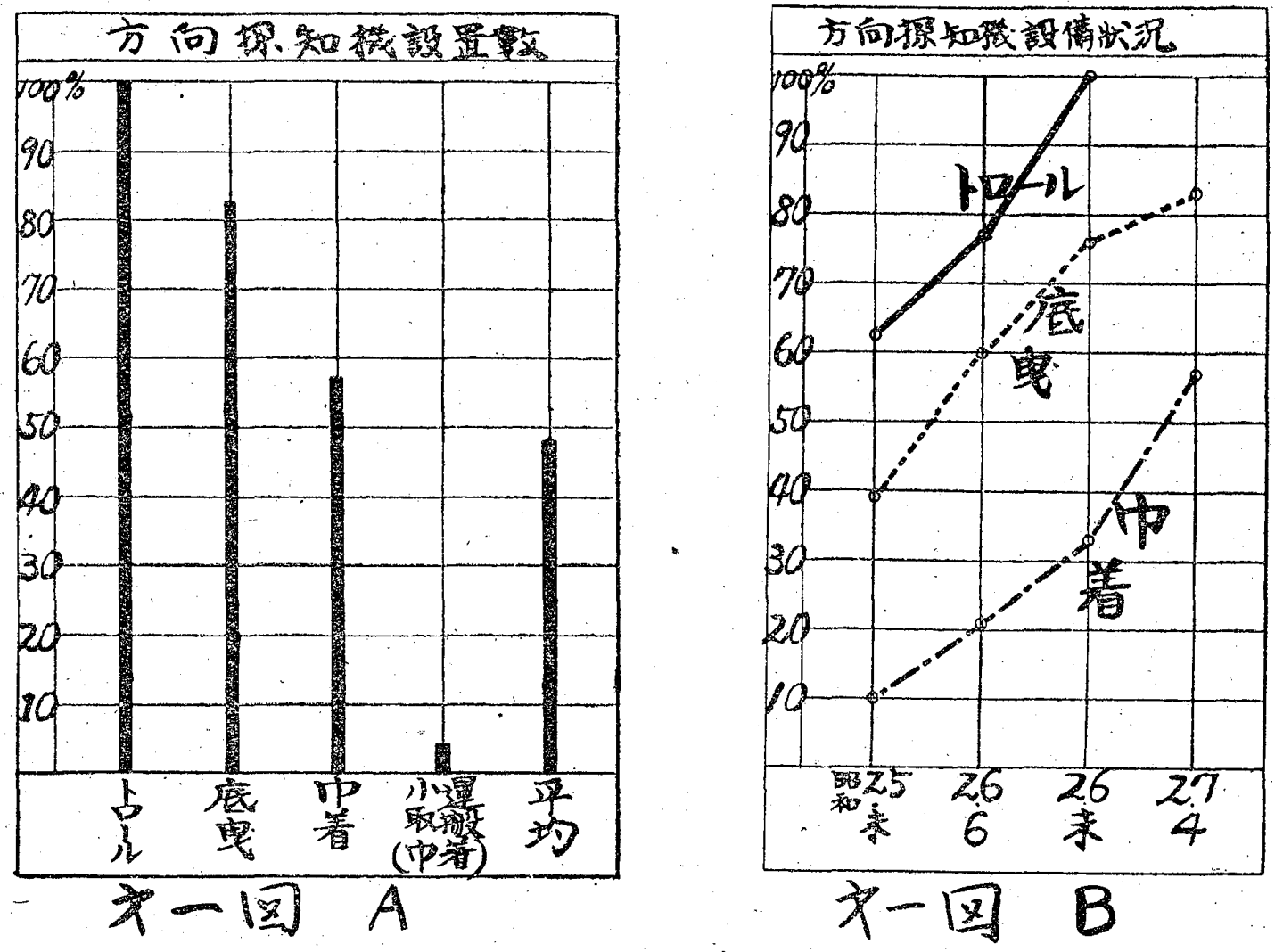

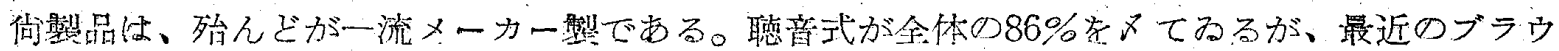

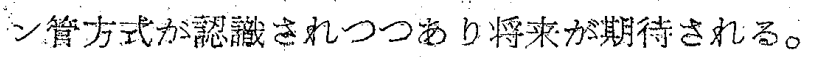

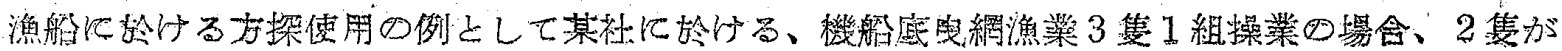

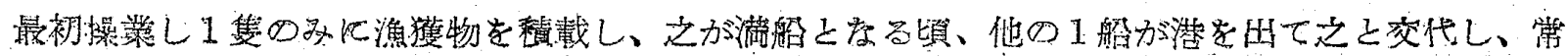

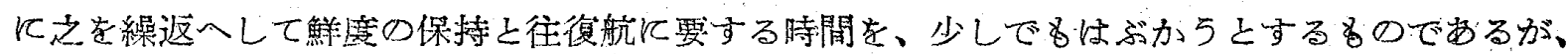


此の時の傆船の会合に方向探知機の果す役目は大きい。

叉巾着網漁船は、沿岸、近海者主漁場之してるる関係上、船位測定は殆んど、沿岸航法飞低つ

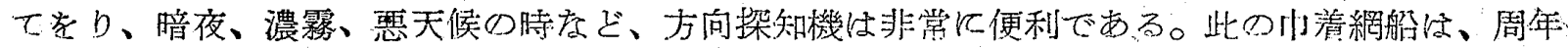
魚を遑つて全国各地を移動するのであるが、夏季の北海淔航路の鯖時期は、ガスが非常に多く、

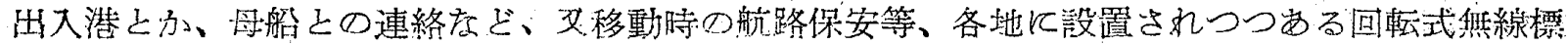

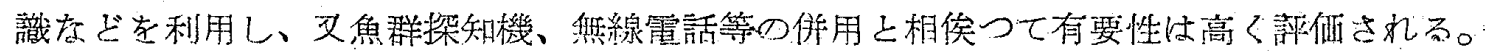

\section{2. 魚群挆知 機}

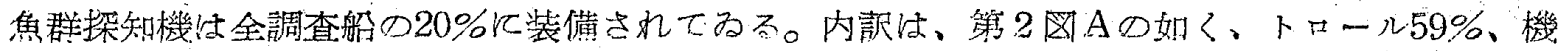
船底电網漁船 2 隻 1 組として $9 \%$ 、巾着網船 2 隻 1 統之して $80 \%$ 、多び巾着関係の、小取船・運

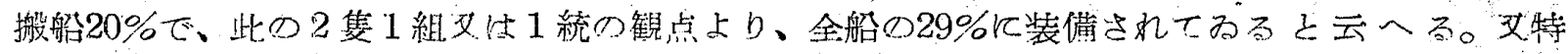

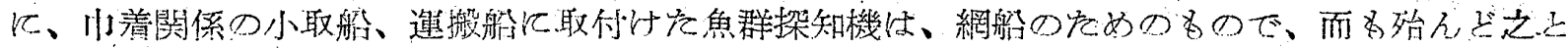

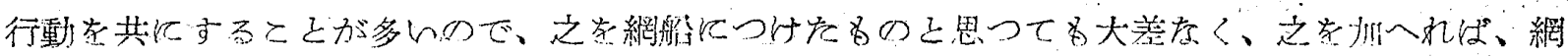

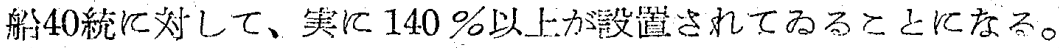
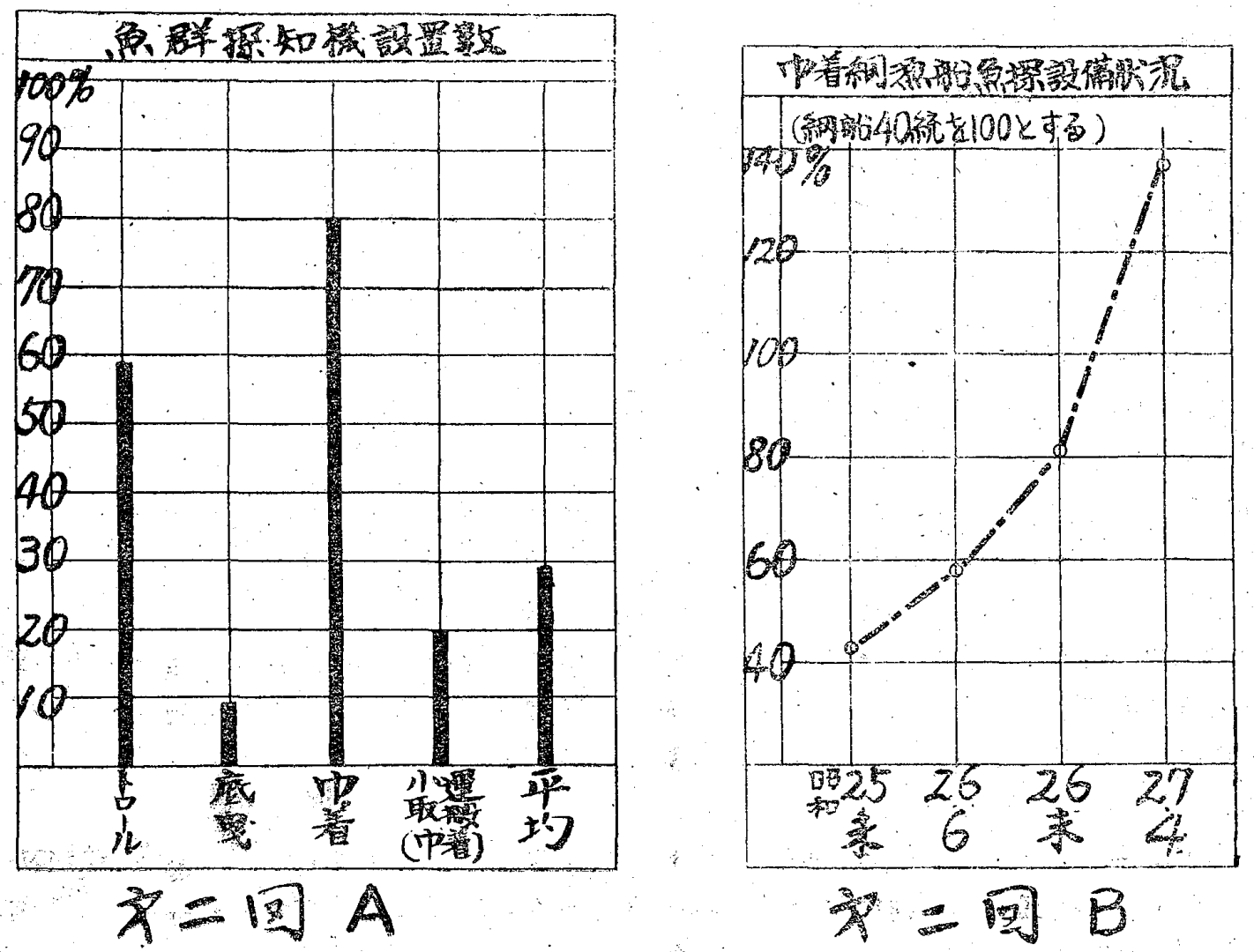

トロール、及び機船底电網漁船の魚群探知機は、その殆んぞが、昭和25年以前に設置されてる るが、灲着関係は、第 2 図Bの如く、昭和27年飞入つて新しく取付けられたもの金全体の40\%以

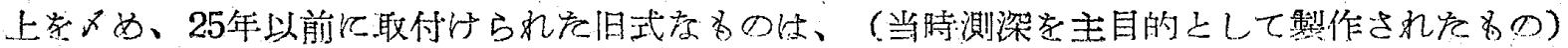

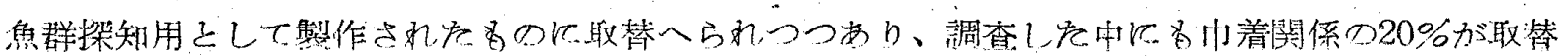
的予定して为觉。

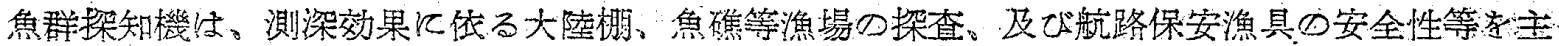

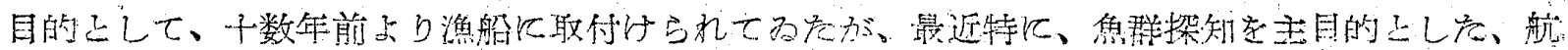





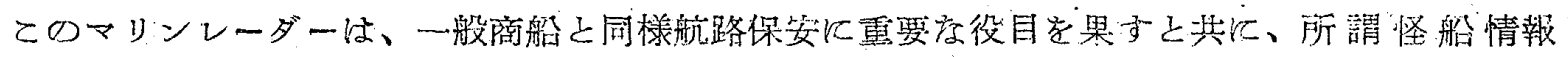

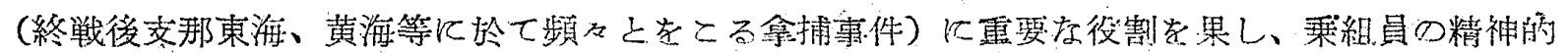

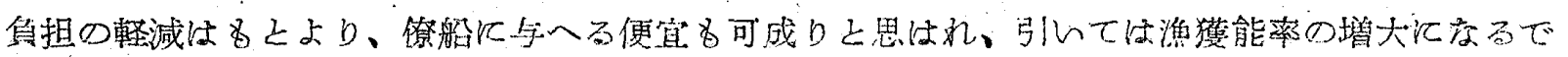
西ら

$$
\text { 綘 锗 }
$$

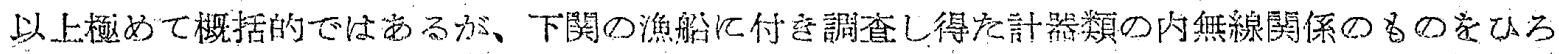

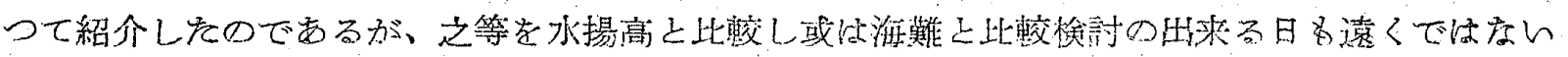

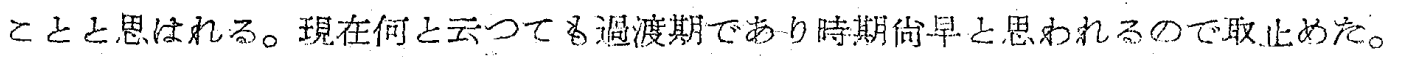

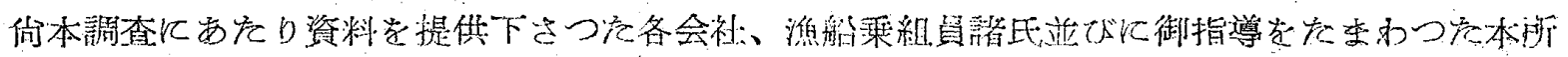
备教官に哚見の謝意を表して此の稿を終石。 